\title{
Gas Chromatography Mass Spectrometry Identification of Labile Radicals Formed during Pyrolysis of Catechool, Hydroquinone, and Phenol through Neutral Pyrolysis Product Mass Analysis
}

\author{
Julien Adounkpe, ${ }^{1}$ Martin Aina, ${ }^{2}$ Daouda Mama, ${ }^{3}$ and Brice Sinsin' \\ ${ }^{1}$ Laboratory of Applied Ecology, Faculty of Agronomic Sciences, University of Abomey-Calavi, 03 BP 3908 Cotonou, Benin \\ ${ }^{2}$ Laboratoire de Science et Technique de l'Eau, Ecole Polytechnique d'Abomey-Calavi, Universite d'Abomey-Calavi, \\ 04 BP 0823 Cotonou, Benin \\ ${ }^{3}$ Laboratoire d'Hydrologie Appliquee, Universite d'Abomey-Calavi, BP 526 Abomey-Calavi, Benin
}

Correspondence should be addressed to Julien Adounkpe; julvictoire@yahoo.com

Received 7 October 2013; Accepted 28 November 2013

Academic Editors: M. Millet and Q. Zhou

Copyright (C) 2013 Julien Adounkpe et al. This is an open access article distributed under the Creative Commons Attribution License, which permits unrestricted use, distribution, and reproduction in any medium, provided the original work is properly cited.

\begin{abstract}
Catechol, hydroquinone, and phenol are known to be environmental pollutants due to their ability to generate environmentally free radicals, which cause millions of deaths worldwide. Recently, efforts have been done to precisely identify the origin and the nature of those free radicals employing EPR-LTMI technique. All the three precursors generate cyclopentadienyl radical as major pyrolysis products and phenoxyl radical as both pyrolysis and photolysis products which were obtained from phenol; ortho-semiquinone and para-semiquinone were seen, respectively, from the pyrolysis of catechol and hydroquinone. However, it has been suspected that the solely use of the EPR-LTMI did not allow the isolation of the more labile radicals that is supposedly terminated by radicalradical or radical-surface interaction. The present study reports the gas chromatography mass analysis of the pyrolysis products from catechol, hydroquinone, and phenol. Naphthalene, indene, and hydroxyindene were observed as the pyrolysis products of hydroquinone, while fluorene, $1 \mathrm{H}$-indenol and its isomer $1 \mathrm{H}$-inden-1-one 2,3 dihydro, acenaphthylene, benzofuran-7-methyl, and benzofuran-2-methyl were observed as pyrolysis products of catechol. Dibenzo dioxin and dibenzo furan were observed from pyrolysis of catechol and hydroquinone. Those products result from the combination of radicals such as cyclopentadienyl, parasemiquinone, ortho-semiquinone, hydroxyl-cyclohexadienyl, phenoxyl, and most importantly Hydroxycyclopentadienyl which was not identified by EPR-LTMI.
\end{abstract}

\section{Introduction}

Combustion-generated Particulate Matter (PM) has been extensively reported in the literature [1-8]. They are known as the cause of environmental pollution with its toll of diseases and deaths [9-16]. Particulate Matter (PM) has been categorized as Fine Particulate Matter (FP) and Ultra-fine Particulate Matter (UFP). FPs have an aerodynamic diameter less than $2.5 \mu \mathrm{m}$ while UFPs have an aerodynamic diameter less than $0.1 \mu \mathrm{m}[17,18]$. The smaller the size of fine particles, the more potent and biologically destructive they are [19-23].
Fine particles' toxicity has been attributed to their association with free radicals [24-26].

Persistent Free Radicals (PFRs) are chemical compounds with one or more unpaired electrons, sufficiently stable towards decomposition, and resistant to further reaction and can exist for long period of time in the atmosphere. These free radicals that potentially include semiquinone-type and phenoxyl-type radicals are highly resonance stabilized and are supposed to form in combustion systems or thermal processes such as burning of cigarette, biomass fuels, fossil fuels, coal, and hazardous materials [18]. The PFRs associated 
with particulate matter of $2.5 \mu \mathrm{m}$ aerodynamic diameter $\left(\mathrm{PM}_{2.5}\right)$ are consistent with semiquinone type radicals [19]. It has also been reported that the precursors of semiquinone type radicals are catechol (CAT), hydroquinone (HQ), and structurally similar compounds found in woods, biomass, fuels, and tobacco [20-26].

From radical stand point, during these past ten years, extensive efforts have been made in identifying PFRs that can be associated with PM [27-30]. Some of these radicals are very labile and terminated without being acquired by the Electron-Paramagnetic Resonance (EPR) associated with the Low Temperature Matrix Isolation (EPR-LTMI) technique employed. However, molecular prove of the formation of such radicals is expected to definitively give an extensive view on radicals formed from combustion of organic matters. This is the main purpose of the present work.

\section{Material and Method}

2.1. Sampling. For the pyrolysis of catechol, hydroquinone, and phenol, the same experimental procedure is almost followed, except for some minor differences due to their vapor pressures. Catechol (CAT) and hydroquinone (HQ) have very low vapor pressures. Thus they needed to be vaporized prior to their pyrolysis. Experiments were carried out by loading HQ, CAT, or phenol ( $>99.5 \%$ pure from Aldrich) into a Pyrex container vaporizer in a constant temperature oven held at $50-75^{\circ} \mathrm{C}$ for the vaporization of the sample of CAT and HQ and at $15^{\circ} \mathrm{C}$ for phenol. To avoid condensation of the vaporized CAT and $\mathrm{HQ}$ samples on the transfer line to the cold finger of the Dewar, the transfer line was insulated and held at temperature of $80-90^{\circ} \mathrm{C}$ employing heating tapes and blankets. All samples were at a total pressure of carrier gas of $\sim 0.1-0.3$ Torr for the low pressure pyrolysis of the precursors and 760 Torr for the atmospheric pyrolysis measured by the online pressure gauges. The experimental setup for the low pressure pyrolysis is described elsewhere (my references). The atmospheric conditions pyrolysis is depicted in Figure 1. The carrier gas used for this research is carbon dioxide. Upon exiting the vaporizer, the vaporized sample entered the tubular-flow quartz reactor (i.d. $=12 \mathrm{~mm}$, length $=$ $40 \mathrm{~mm}$ ) located in an electrically heated furnace. Radical accumulation time ranged from 10 to 12 minutes, starting point of the saturation. Reagents are pumped by the means of rotary pumps at a pressure of 0.1 Torr through the electrically heated pyrolysis zone. Pyrolysis products are condensed onto the cold finger of the Dewar placed in the EPR cavity and cooled by liquid nitrogen. Carbon dioxide can be introduced at a given flow as a main carrier gas into the pyrolysis zone. Once the sample is loaded in the vaporizer, the sample, the transfer line, and the Dewar were flushed long enough under the carrier gas flow $\left(\mathrm{CO}_{2}\right)$ to remove oxygen from the sample and the transfer line. The flushing is done by the rough pump at a rate of $60 \mathrm{cc} / \mathrm{min}$. Given that CAT and HQ have very low vapour pressure, slightly heating their samples during the flushing period helps to get rid of absorbed/adsorbed oxygen. Phenol's samples do not need the preheating because of phenol's high vapour pressure. After sufficient flushing, the

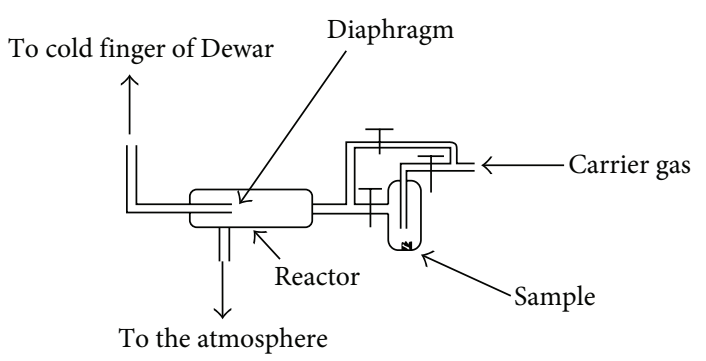

FIgURE 1: Assembly for atmospheric pyrolysis experiments.

vaporizer hosted by a furnace was set at the sample vaporizing temperatures, 50 or $75^{\circ} \mathrm{C}$ for CAT and $\mathrm{HQ}$ and $15^{\circ} \mathrm{C}$ for phenol.

The flow meters in the system allow monitoring the time of residence of the vaporized sample in the pyrolysing reactor held at the experimental temperature by a thermoelectric furnace. The radical accumulation starts when the Dewar is filled with liquid nitrogen. A rotary pump is used to pump the pyrolyzed products through the liquid nitrogen cooled Dewar. Frozen radicals onto the cooled finger of the Dewar can be observed by the dropping of the total reagent pressure (from 0.1 Torr to $10^{-3}$ Torr) and most of the time by the slight change of cold finger color. The accumulation lasts generally 10 to 12 minutes during which EPR spectra of frozen radicals are acquired every minute. The end of the accumulation of radicals is marked by the nonincreasing of EPR signal intensity of the radicals. At the end of the accumulation, the carrier gas flow was stopped, and the sample vaporizer was closed. More EPR spectra of total radical intensity were then registered in the absence of thermal noise generated by the interaction of the hot gas flow with the cooled finger of the Dewar. This is the time in the experiment where the power dependence of radical is achieved. After acquisition of the radical spectra, the Dewar was removed from the EPR cavity under liquid nitrogen temperature.

The pyrolysis products are thereafter dissolved in approximately $5 \mathrm{~cm}^{3}$ ethanol under hood and dried up to $1 \mathrm{~cm}^{3}$. one $\mu \mathrm{L}$ of the solution is injected in a GC-MS.

The radical intensity is calculated employing the method of double integration of the first derivative signal and compared with a standard sample of 2,2-di(4tertoctylphenyl)-1-picrylhydrazyl (DPPH or 1,1-diphenyl-2picrylhydrazyl (DPPH).

2.2. Products Mass Analysis. Products were analyzed using an Agilent Technologies 6890N GC system coupled with a 5973 Masse Selective Detector. Products separation was completed employing a $30 \mathrm{~m}, 0.25 \mathrm{~mm}$ i.d., and $0.25 \mu \mathrm{m}$ film thickness column (Restek, Rtx-5MS) with a temperature program ramp from -60 to $300^{\circ} \mathrm{C}$ at $15^{\circ} \mathrm{C} / \mathrm{min}$. The injection port was operated at the temperature of $90^{\circ} \mathrm{C}$ for CAT and $\mathrm{HQ}$ and $50^{\circ} \mathrm{C}$ for phenol. Detection of products was obtained on the Agilent 5973 Mass Selective Detector operating in fullscan mode from 15 to $350 \mathrm{amu}$. The GC/MS software, an Automated Mass Spectral Deconvolution and Identification 


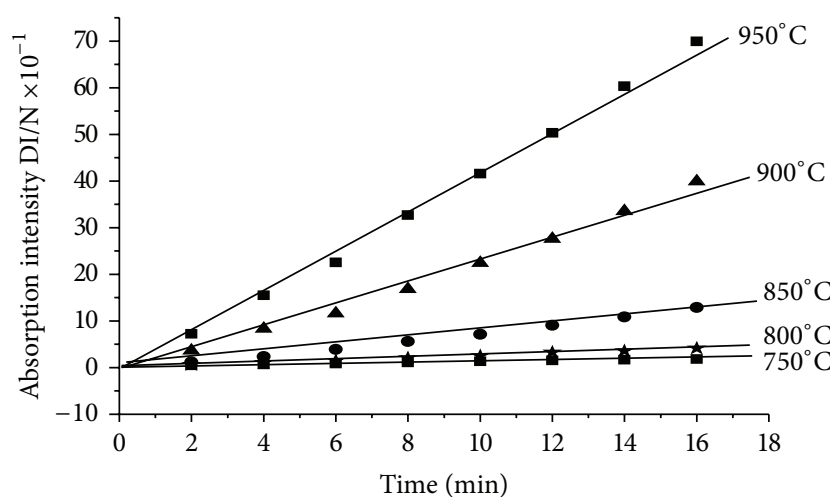

FIGURE 2: Time dependence of radicals intensity from the pyrolysis of phenol from 750 to $950^{\circ} \mathrm{C}$. A linear trend with excellent correlation intensity versus time was observed in the entire temperature domain.

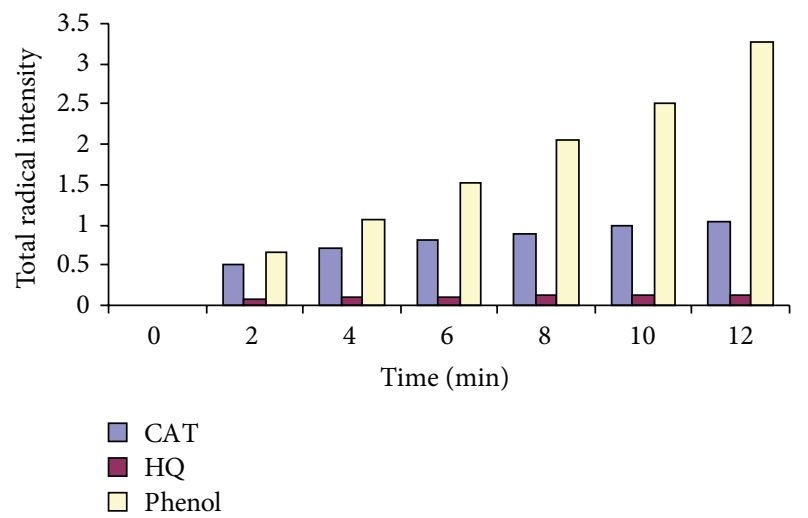

FIgURE 3: A comparative total radical intensity yields from 0 to $12 \mathrm{~min}$ accumulation time of radicals from the pyrolysis of CAT(blue), HQ ( red), and phenol (yellow). HQ shows the lowest yield. While total radical intensity from phenol keeps an increasingly linear trend, saturation is reached at approximately $10 \mathrm{~min}$ of total radical accumulation from CAT and HQ.

System (AMDIS-DSWA NIST. 1997), was used to identify the products of the pyrolysis of CAT, HQ and Phenol.

\section{Result and Discussion}

3.1. Time Dependence of Total Radical Accumulation. For each sample and for a given pyrolysis temperature, pyrolysis products are accumulated for 10 to 12 minutes and EPR spectra acquired every minute. The radical intensity is thereafter calculated by transferring a given EPR spectrum to SimFonia software (http://www.bruker-biospin.com/simfonia.html). A double integration of the spectrum gives its surface area. The latter was divided by the surface area of the DPPH used as reference to account for the conversion time, receiver gain, number of data points, and sweep width, in sorting the normalisation of the spectra intensities.

Beside its natural occurrence [32-35], phenol is a product of the thermal degradation of CAT and HQ $[27,36]$ and is abundantly found in mainstream tobacco smoke [37].

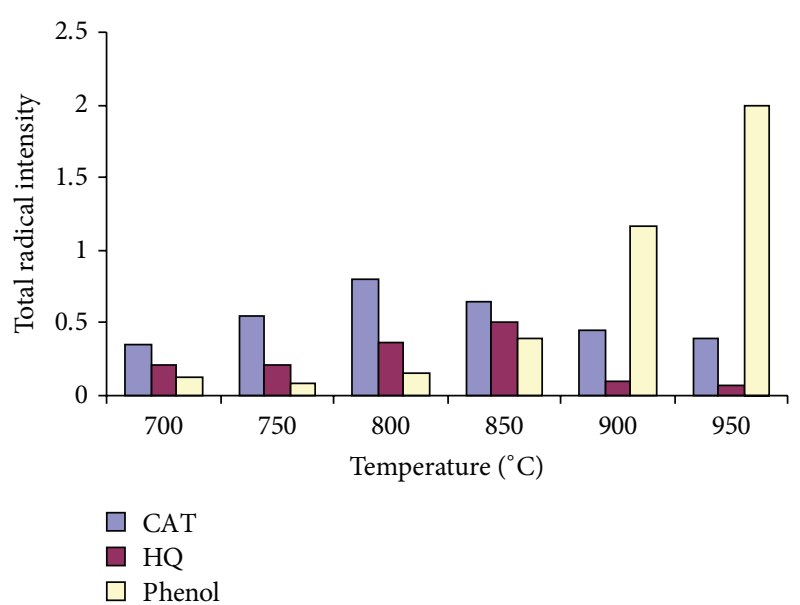

FIgUre 4: Temperature dependence of total radical yield. CAT values to the scale, and HQ values have been multiplied by 2 and phenol's value divided by 10 . CAT and HQ have the same trends with maximum at $800^{\circ} \mathrm{C}$ and $850^{\circ} \mathrm{C}$ while phenol's values have a sudden increase by $800^{\circ} \mathrm{C}$.

Its pyrolysis, as it can be seen from Figure 2, shows a linear increase trend with all pyrolysis temperatures.

Unlike CAT and HQ, accumulation of the pyrolysis products of phenol shows no saturation which means accumulation is possible beyond 16 minutes with a fine tune of the EPR resonator, while for CAT and HQ saturation is reached after 10 to 12 minutes of their pyrolysis product accumulation. This phenomenon can be due to several reasons. The phenol high vapour pressure in comparison to those of CAT and HQ favours a steady feed of material to the reactor throughout the experiment, while CAT and HQ low vapour pressure leads to a quick saturation. Phenol molecular structure compared to those of CAT and HQ renders its thermal degradation easier than that of the others [36], leading to limited radicalradical recombination that facilitates longer accumulation time. Furthermore, by pyrolysis, CAT and HQ decompose to phenol and other compounds [38] in which their presence may cryogenically clog the EPR cavity.

The thermal degradation of HQ scheme shows, on the left hand side, that phenol will decompose to yield phenyl, phenoxy, and CPD. Phenol thermal degradation leads to phenoxy radical by elimination of the hydrogen atom of the hydroxyl group of phenol. Further reaction of phenoxy proceeds by CO elimination to form CPD [39]. In our gasphase phenol thermal degradation study, CPD and phenoxy radicals are, respectively, identified as pyrolysis products and their EPR gas-phase spectra are acquired [39-42].

Unlike the pyrolysis of phenol, the time dependence of radical intensity from the pyrolysis of HQ and CAT showed saturation towards the end of the accumulation as depicted by Figure 3 .

3.2. Temperature Dependence of Total Radical Accumulation. As it was seen, the pyrolysis of phenol from 400 to $1000^{\circ} \mathrm{C}$ shows a linear time dependence of radical signal intensity (Figure 3). However, the temperature dependence of radical 


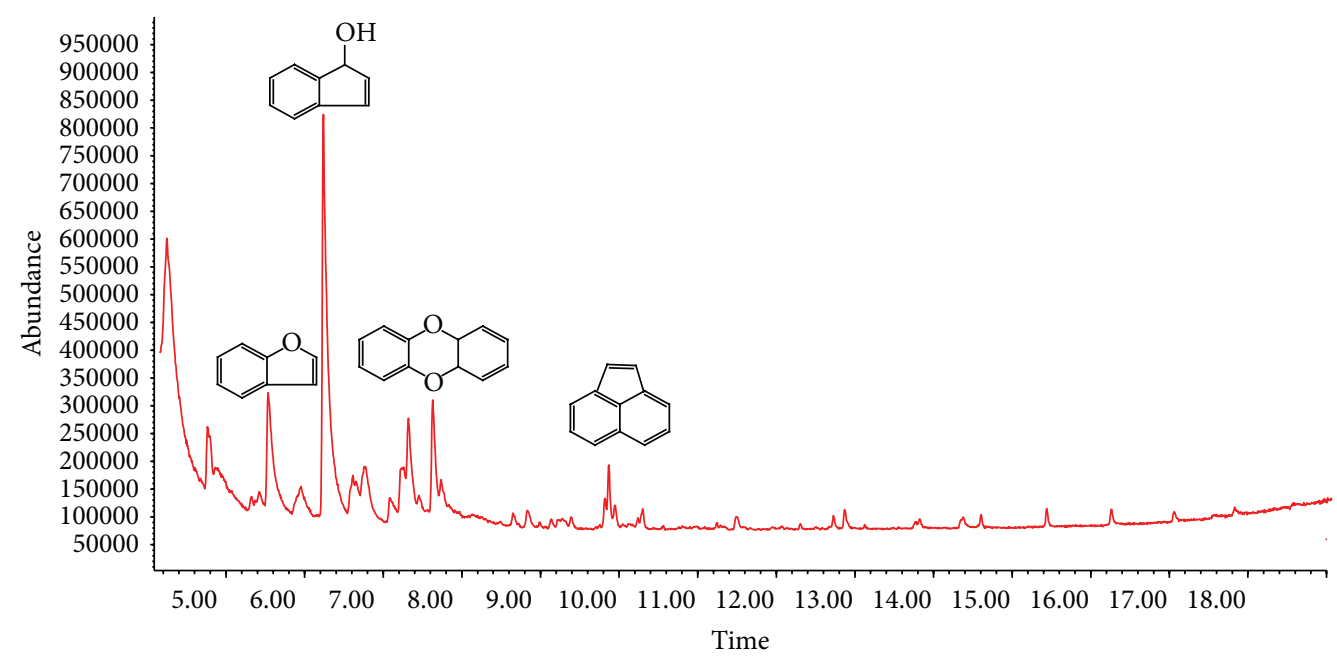

FIGURE 5: Gas chromatogram of pyrolysis products of catechol.

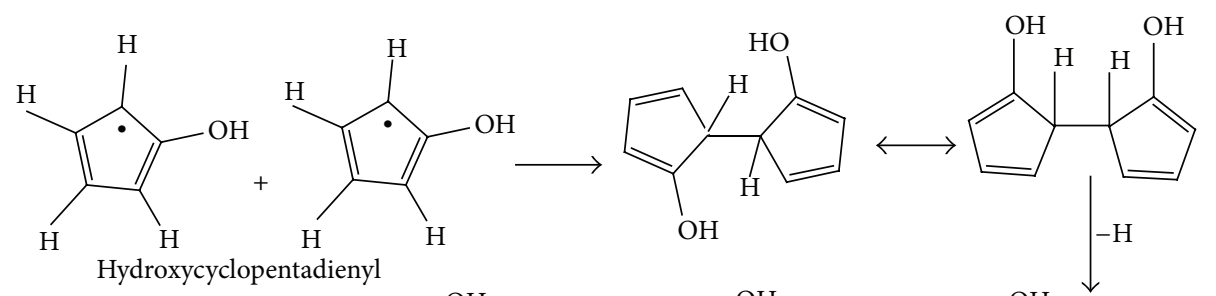

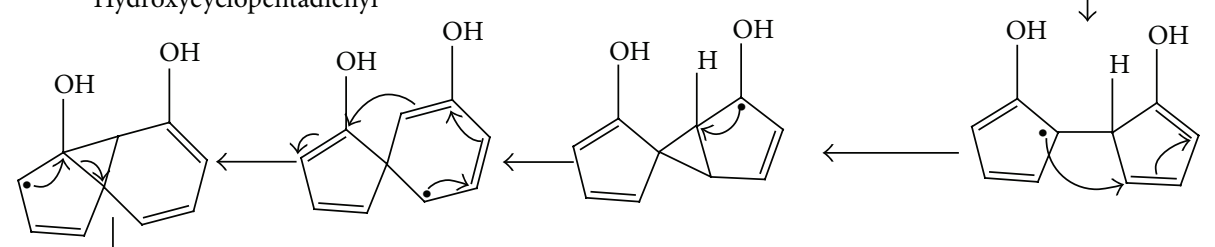

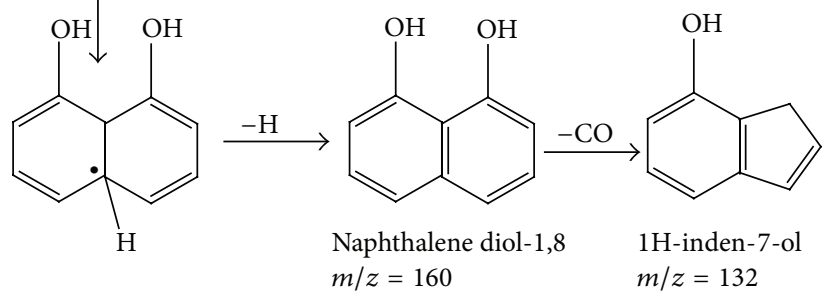

Scheme 1: Proposed mechanism of the formation of napthalene diol-1,8 and 1H-inden-7-ol.

intensity from phenol shows a sudden increase from $700^{\circ} \mathrm{C}$, while the temperature dependence of CAT pyrolysis showed an increase in signal intensity from 300 to $800^{\circ} \mathrm{C}$, followed by a decrease above $800^{\circ} \mathrm{C}$ as shown in Figure 4. The thermal degradation of CAT should yield o-semiquinone (o-SQ), $\mathrm{CPD}$, phenoxy, and hydroxycyclopentadienyl (HO-CPD) as the most likely Persistent Free Radicals (PFRs). We have positively identified and acquired o-SQ and CPD radicals EPR spectra.

The temperature dependence of $\mathrm{HQ}$ pyrolysis showed an increase in signal intensity from 300 to $850^{\circ} \mathrm{C}$, followed by a decrease above $850^{\circ} \mathrm{C}$ (Figure 4). p-semiquinone (p-SQ), $\mathrm{CPD}$, phenoxy, and hydroxycyclopentadienyl (HO-CPD) radicals are more likely the most Persistent Free Radicals (PFRs) to form from the pyrolysis/photolysis of HQ. We have positively identified and acquired $\mathrm{p}-\mathrm{SQ}$ and $\mathrm{CPD}$ radicals EPR spectra $[39,40]$.

It has been demonstrated that the pyrolysis of CAT and HQ promotes formation of methyl $\left(\mathrm{CH}_{3}\right)$, ethyl $\left(\mathrm{CH}_{3} \mathrm{CH}_{2}\right)$ $[43,44]$, and acetylene [44] that contributed to the formation of PAHs. In our effort to identify persistent free radicals formed from the pyrolysis of CAT, HQ, and phenol, we have had a close look at the nonradical products formed from the combination of radicals either labile or persistent. Basically, some radicals from the pyrolysis/photolysis of CAT and HQ are suspected to be labile to the point where acquisition of their EPR spectra was not possible before they were terminated either by radical-radical reaction or radical-surface interaction. Thus a mass analysis of the pyrolysis/photlysis products of CAT and HQ was performed. Figure 5 is a 
<smiles>Oc1ccccc1</smiles>
Hydroxycyclopentadienyl Cyclopentadienyl<smiles>OC1=CC=CC1C1C=CC=C1</smiles><smiles>OC1=CC=CC1C1C=CC=C1</smiles><smiles>CC1=C(O)C2(C=C1)C1C=CC2C12CCCC2</smiles><smiles>[14CH3]C12C=CC=CC1C(O)=CC=C2</smiles><smiles>OCC=C1C2CC3CC(C2)CC1(CO)C3</smiles><smiles>Cc1cccc2ccccc12</smiles><smiles>CC(=O)OC(=O)c1ccc2c(c1)C=CC2</smiles>

1-Hydroxynaphthalene
$m / z=144$

Indene

$m / z=116$

Scheme 2: Proposed mechanism of the formation of 1-hydroxynaphthalene from the condensation of one molecule of CPD and one molecule of HydroxyCPD followed by the formation of $1 \mathrm{H}$-indene by elimination of $\mathrm{CO}$ from the formed hydroxynaphthalene.

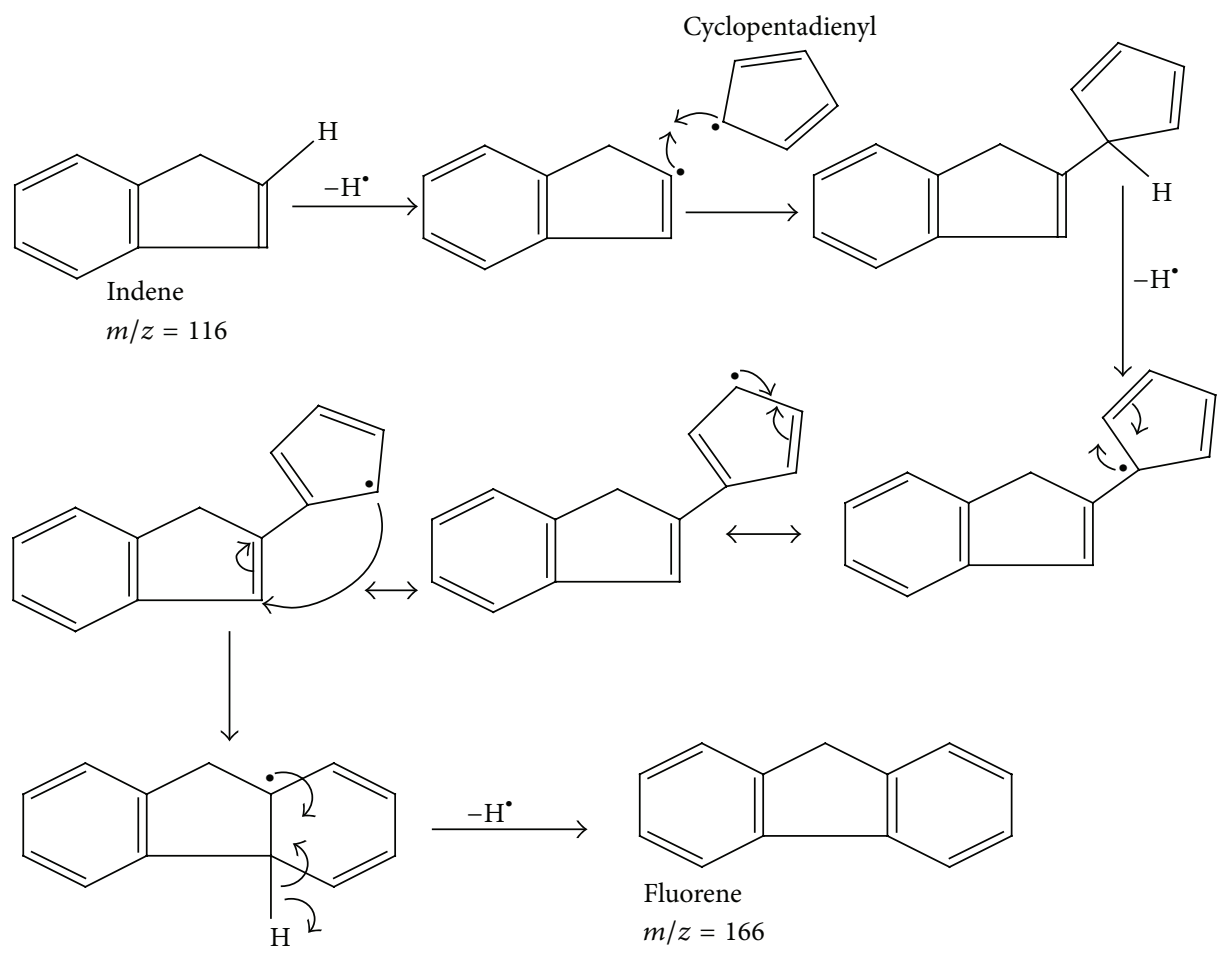

Scheme 3: Formation of fluorene. It starts with $\mathrm{H}$-radical abstraction from indene followed by its condensation with a cyclopentadienyl radical followed by the cycling with elimination of a second $\mathrm{H}$-radical.

chromatogram of CAT pyrolysis products depicting the major neutral compounds formed.

The GC-MS analysis of the pyrolysis products of CAT revealed the formation of fluorene (Scheme 3$)(\mathrm{m} / \mathrm{z}=166)$ and $1 \mathrm{H}$-indenol $(\mathrm{m} / \mathrm{z}=132)$ and its isomer $1 \mathrm{H}$-inden-1-one,
2,3_ dihydro, acenaphthylene $(m / z=152)$, benzofuran-7methyl, and benzofuran-2-methyl $(m / z=132)$.

From hydroquinone, a computer-generated hydroxycyclopentadienyl (HO-CPD) radical EPR spectrum, a fiveline spectrum with intensity distribution $1: 4: 6: 4: 1$ was 


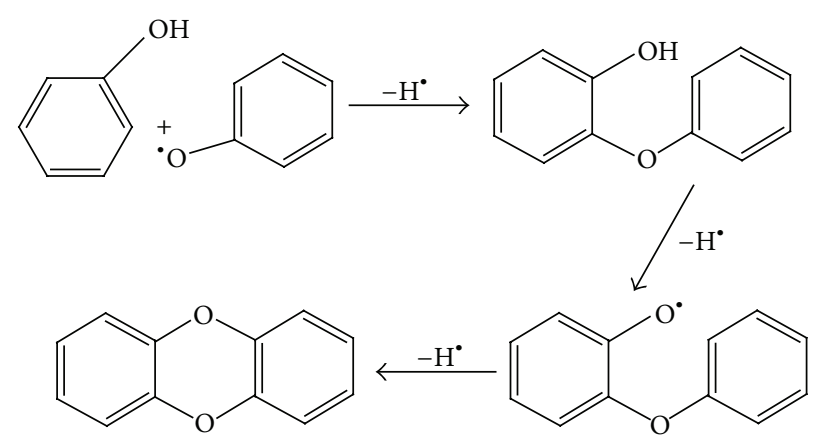

SCHEME 4: Formation DD from radical-radical condensation reactions [31].

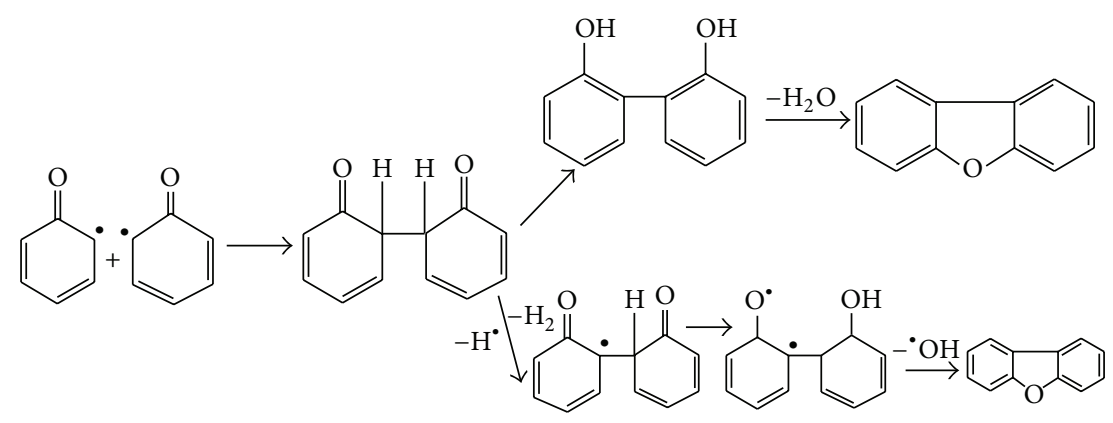

SCHeme 5: Formation of DF from radical-radical recombination reactions [31].

compared with the EPR spectra from the pyrolysis of HQ in all temperature regions $\left(400-1000^{\circ} \mathrm{C}\right)$ [42]. There was no match. However, the GC-MS analysis of the atmospheric pressure pyrolysis products of HQ revealed the formation of, in addition to naphthalene $(\mathrm{m} / \mathrm{z}=130)$, indene $(\mathrm{m} / \mathrm{z}=$ 116) and Hydroxyindene $(\mathrm{m} / z=132)$.They are supposed to result from $\mathrm{CO}$ elimination from either Hydroxynaphthalene $(m / z=144)$ or Dihydroxynaphthalene $(m / z=160)$. Hydroxynaphthalene and ihydroxynaphthalene can result from the condensation of one molecule of $\mathrm{CPD}$ and one of HO$\mathrm{CPD}$ and the condensation of two molecules of HO-CPD respectively. Also dibenzo dioxin and dibenzo furan were observed.

The formation of indene and hydroxyindene during the pyrolysis of HQ is the evidence of OHCPD gas-phase formation. Therefore OHCPD is formed but was not persistent enough to acquire its EPR spectrum with the various techniques we used in the previous studies [39, 40, 42].

Fluorene is second to naphthalene in the family of polyaromatic hydrocarbons (PAHs).

Fluorene detection as the pyrolysis products of CAT is a confirmation that $\mathrm{CPD}$ radicals are formed during the pyrolysis/photolysis of CAT as demonstrated in previous studies [39, 40, 42].

(i) The detection of $1 \mathrm{H}$-indenol gives evidence of the formation of labile radicals such as Hydroxycyclopentadienyl radical while that of fluorene confirms not only the formation of CPD radical but also of aliphatic radicals such as ethenyl and acetylene radicals [44]. Scheme 1 presents the mechanism of $1 \mathrm{H}$-indenol formation. Its formation proceeds by condensation reaction of two hydroxy-CDP radicals with intermediary formation of naphthalene-diol followed by $\mathrm{CO}$ elimination.

Formation of dibenzodioxin (DD) results from the condensation of one molecule of phenol and one phenoxyl radical followed by successive $\mathrm{H}$-radical abstraction and cycling as depicted in Scheme 4.

Scheme 5 shows the formation of DF as the results of radical-radical recombination of two keto-forms of phenoxyl radical to a dimer intermediate. The latter intermediate can either tautomerize to 2,2-dihydroxybiphenyl followed by an intramolecular water elimination process to form DF (upper pathway in Scheme 5) or undergo a hydrogen abstraction followed by intramolecular interring displacement of hydroxyl radical to form DF (lower pathway in Scheme 5)

\section{Conclusion}

The present study, by combining LTMI-EPR and GC-MS, has shined light on, and thus completing, CAT, HQ, and phenol thermal decomposition understanding. The mass analysis permits to identify molecules such as naphthalene. The experimental identification of those compounds gives the proof of how they are formed. Radical-radical, radicalneutral molecule and even radical-wall interactions are plausible explanation of the molecular gas phase formation. Thus, naphthalene would result from the condensation of two molecules of CPD radical, 1-hydroxynaphthalene from 
the condensation of one HO-CPD and one CPD, followed by elimination of $\mathrm{CO}$ to yield indene (Scheme 2).

\section{Acknowledgments}

The authors greatly acknowledge the partial support to this research by the National Science Foundation (NSF) Grant CTS-0317094, Philip Morris USA, the British American Tobacco, and Patrick F. Boyd chair held by Dr. Barry Dellinger, the Director of the Interdepartmental Colloquium on Environment. The authors are deeply indebted to Dr. Dellinger and Dr. Lavrent Khachatryan their mentors, both from the Chemistry Department of Louisiana State University (USA) for providing them with a very nice working environment and support.

\section{References}

[1] U. S. EPA, National Emission Trends (NET) Database, Emission Factor and Inventory Group, Research Triangle Park, Raleigh, NC, USA, 2000.

[2] P. M. Fine, G. R. Cass, and B. R. T. Simoneit, "Chemical characterization of fine particle emissions from the fireplace combustion of woods grown in the Southern United States," Environmental Science and Technology, vol. 36, no. 7, pp. 14421451, 2002.

[3] J. M. Samet, F. Dominici, F. C. Curriero, I. Coursac, and S. L. Zeger, "Fine particulate air pollution and mortality in 20 U.S. cities, 1987-1994," The New England Journal of Medicine, vol. 343, no. 24, pp. 1742-1749, 2000.

[4] D. W. P. I. Dockery, X. Xu, J. D. Spengler, J. H. Ware, and M. A. Fay, "An association between air pollution and mortality in six U.S. cities," The New England Journal of Medicine, vol. 329, no. 24, pp. 1753-1759, 1993.

[5] M. Jamriska, "Relation between indoor and outdoor exposure to fine particles near a busy Arterial Road," Indoor Air, vol. 9, no. 2, pp. 75-84, 1999.

[6] K. Katsouyanni, G. Touloumi, E. Samoli et al., "Confounding and effect modification in the short-term effects of ambient particles on total mortality: results from 29 European cities within the APHEA2 project," Epidemiology, vol. 12, no. 5, pp. 521-531, 2001.

[7] C. A. Pope III, R. T. Burnett, M. J. Thun et al., "Lung cancer, cardiopulmonary mortality, and long-term exposure to fine particulate air pollution," The Journal of the American Medical Association, vol. 287, no. 9, pp. 1132-1141, 2002.

[8] J. Kaiser, "Evidence mounts that tiny particles can kill," Science, vol. 289, no. 5476, pp. 22-23, 2000.

[9] J. Schwartz, "Assessing confounding, effect modification, and thresholds in the association between ambient particles and daily deaths," Environmental Health Perspectives, vol. 108, no. 6, pp. 563-568, 2000.

[10] W. W. H. Organization, Air Quality Guidelines for Europe 1996, Particulate Matter, WHO, 1997.

[11] R. M. Harrison, J. P. Shi, S. Xi et al., "Measurement of number, mass and size distribution of particles in the atmosphere," Philosophical Transactions of the Royal Society A, vol. 358, no. 1775, pp. 2567-2580, 2000.

[12] M. J. Kleeman, J. J. Schauer, and G. R. Cass, "Size and composition distribution of fine particulate matter emitted from motor vehicles," Environmental Science and Technology, vol. 34, no. 7, pp. 1132-1142, 2000.

[13] A. Nemmar, H. Vanbilloen, M. F. Hoylaerts, P. H. M. Hoet, A. Verbruggen, and B. Nemery, "Passage of intratracheally instilled ultrafine particles from the lung into the systemic circulation in hamster," American Journal of Respiratory and Critical Care Medicine, vol. 164, no. 9, pp. 1665-1668, 2001.

[14] L. Calderón-Garcidueñas, A. Mora-Tiscareño, L. A. Fordham et al., "Canines as sentinel species for assessing chronic exposures to air pollutants: part 1 . Respiratory pathology," Toxicological Sciences, vol. 61, no. 2, pp. 342-355, 2001.

[15] L. Calderón-Garcidueñas, T. M. Gambling, H. Acuña et al., "Canines as sentinel species for assessing chronic exposures to air pollutants: part 2. Cardiac pathology," Toxicological Sciences, vol. 61, no. 2, pp. 356-367, 2001.

[16] B. Dellinger, W. A. Pryor, R. Cueto, G. L. Squadrito, V. Hegde, and W. A. Deutsch, "Role of free radicals in the toxicity of airborne fine particulate matter," Chemical Research in Toxicology, vol. 14, no. 10, pp. 1371-1377, 2001.

[17] Z. Meng and Q. Zhang, "Oxidative damage of dust storm fine particles instillation on lungs, hearts and livers of rats," Environmental Toxicology and Pharmacology, vol. 22, no. 3, pp. 277-282, 2006.

[18] G. P. Huffman, F. E. Huggins, N. Shah et al., "Characterization of fine particulate matter produced by combustion of residual fuel oil," Journal of the Air and Waste Management Association, vol. 50, no. 7, pp. 1106-1114, 2000.

[19] G. L. Squadrito, R. Cueto, B. Dellinger, and W. A. Pryor, "Quinoid redox cycling as a mechanism for sustained free radical generation by inhaled airborne particulate matter," Free Radical Biology and Medicine, vol. 31, no. 9, pp. 1132-1138, 2001.

[20] C. G. Nolte, J. J. Schauer, G. R. Cass, and B. R. T. Simoneit, "Highly polar organic compounds present in wood smoke and in the ambient atmosphere," Environmental Science and Technology, vol. 35, no. 10, pp. 1912-1919, 2001.

[21] G. E. Troughton, J. F. Manville, and S. Z. Chow, "Lignin utilization. II. Resin properties of 4-alkyl-substituted catechol compounds',' Forest Products Journal, vol. 22, no. 9, pp. 108-110.

[22] R. Font, M. Esperanza, and A. N. García, "Toxic by-products from the combustion of Kraft lignin,” Chemosphere, vol. 52, no. 6, pp. 1047-1058, 2003.

[23] M. D. Hays, P. M. Fine, C. D. Geron, M. J. Kleeman, and B. K. Gullett, "Open burning of agricultural biomass: physical and chemical properties of particle-phase emissions," Atmospheric Environment, vol. 39, no. 36, pp. 6747-6764, 2005.

[24] R. Visser, A. A. M. Harbers, A. Hovestad, and T. W. Stevens, "Identification of organic compounds in waste water of wood gasifiers with capillary gas chromatography',' in Proceedings of the 6th International Symposium on Capillary Chromatography, pp. 281-287, 1985.

[25] P. M. Fine, G. R. Cass, and B. R. T. Simoneit, "Chemical characterization of fine particle emissions from the fireplace combustion of wood types grown in the midwestern and Western United States," Environmental Engineering Science, vol. 21, no. 3, pp. 387-409, 2004.

[26] P. M. Fine, G. R. Cass, and B. R. T. Simoneit, "Chemical characterization of fine particle emissions from fireplace combustion of woods grown in the northeastern United States," Environmental Science and Technology, vol. 35, no. 13, pp. 2665$2675,2001$.

[27] H. Truong, S. Lomnicki, and B. Dellinger, "Mechanisms of molecular product and persistent radical formation from the 
pyrolysis of hydroquinone," Chemosphere, vol. 71, no. 1, pp. 107113, 2008.

[28] W. A. Pryor, D. G. Prier, and D. F. Church, "Electron-spin resonance study of mainstream and sidestream cigarette smoke: nature of the free radicals in gas-phase smoke and in cigarette tar," Environmental Health Perspectives, vol. 47, pp. 345-355, 1983.

[29] W. A. Pryor, B. J. Hales, P. I. Premovic, and D. F. Church, “The radicals in cigarette tar: their nature and suggested physiological implications," Science, vol. 220, no. 4595, pp. 425-427, 1983.

[30] L.-Y. Zang, K. Stone, and W. A. Pryor, "Detection of free radicals in aqueous extracts of cigarette tar by electron spin resonance," Free Radical Biology and Medicine, vol. 19, no. 2, pp. 161-167, 1995.

[31] C. S. Evans and B. Dellinger, "Mechanisms of dioxin formation from the high-temperature pyrolysis of 2-chlorophenol," Environmental Science and Technology, vol. 37, no. 7, pp. 1325-1330, 2003.

[32] A. J. Shariff, R. W. Lowe, D. Berthiaume, J. R. G. Bryce, and R. A. N. Mclean, "Unexpected source of phenol in the sulfur-free semichemical pulping of hardwood," Tappi journal, vol. 72, no. 3, pp. 177-183, 1989.

[33] J. B. Luten, J. M. Ritskes, and J. M. Weseman, "Determination of phenol, guaiacol and 4-methylguaiacol in wood smoke and smoked fish-products by gas-liquid chromatography," Zeitschrift für Lebensmittel-Untersuchung und -Forschung, vol. 168, no. 4, pp. 289-292, 1979.

[34] W. S. Schlotzhauer, R. M. Martin, M. E. Snook, and R. E. Williamson, "Pyrolytic studies on the contribution of tobacco leaf constituents to the formation of smoke catechols," Journal of Agricultural and Food Chemistry, vol. 30, no. 2, pp. 372-374, 1982.

[35] S. G. Carmella, S. S. Hecht, T. C. Tso, and D. Hoffmann, "Roles of tobacco cellulose, sugars, and chlorogenic acid as precursors to catechol in cigarette smoke," Journal of Agricultural and Food Chemistry, vol. 32, no. 2, pp. 267-273, 1984.

[36] N. D. Marsh, E. B. Ledesma, A. K. Sandrowitz, and M. J. Wornat, "Yields of polycyclic aromatic hydrocarbons from the pyrolysis of catechol [ortho-dihydroxybenzene]: temperature and residence time effects," Energy and Fuels, vol. 18, no. 1, pp. 209-217, 2004.

[37] E. Roemer, R. Stabbert, K. Rustemeier et al., "Chemical composition, cytotoxicity and mutagenicity of smoke from US commercial and reference cigarettes smoked under two sets of machine smoking conditions," Toxicology, vol. 195, no. 1, pp. 3152, 2004.

[38] B. Shukla and M. Koshi, "A highly efficient growth mechanism of polycyclic aromatic hydrocarbons," Physical Chemistry Chemical Physics, vol. 12, no. 10, pp. 2427-2437, 2010.

[39] L. Khachatryan, J. Adounkpe, Z. Maskos, and B. Dellinger, "Formation of cyclopentadienyl radical from the gas-phase pyrolysis of hydroquinone, catechol, and phenol," Environmental Science and Technology, vol. 40, no. 16, pp. 5071-5076, 2006.

[40] J. G. Adounkpe, Environmentally persistent free radicals from the pyrolysis of cathecol, hydroquinone, phenol and tobacco [Ph.D. dissertation], Louisiana State University, Baton Rouge, La, USA, 2008.

[41] L. Khachatryan, J. Adounkpe, and B. Dellinger, "Formation of phenoxy and cyclopentadienyl radicals from the gas-phase pyrolysis of phenol," Journal of Physical Chemistry A, vol. 112, no. 3, pp. 481-487, 2008.
[42] L. Khachatryan, J. Adounkpe, R. Asatryan, and B. Dellinger, "Radicals from the gas-phase pyrolysis of catechol: 1. osemiquinone and ipso-catechol radicals," Journal of Physical Chemistry A, vol. 114, no. 6, pp. 2306-2312, 2010.

[43] T. Sakai and M. Hattori, "Thermal decomposition of catechol, hydroquinone and resorsinol," Chemistry Letters, pp. 1153-1156, 1976.

[44] E. B. Ledesma, N. D. Marsh, A. K. Sandrowitz, and M. J. Wornat, "An experimental study on the thermal decomposition of catechol," Proceedings of the Combustion Institute, vol. 29, pp. 2299-2306, 2002. 

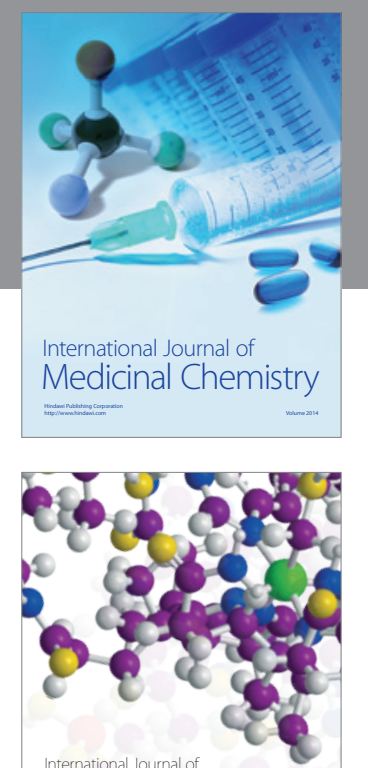

\section{Carbohydrate} Chemistry

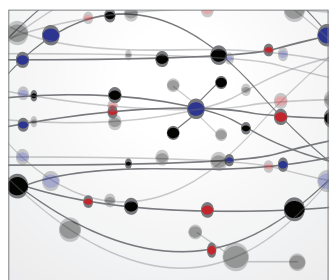

The Scientific World Journal
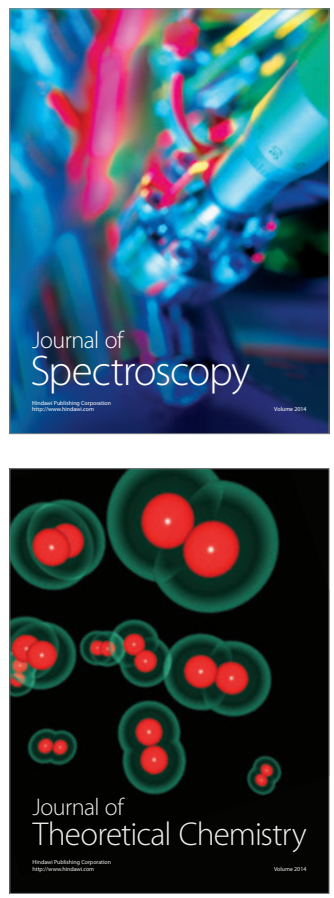
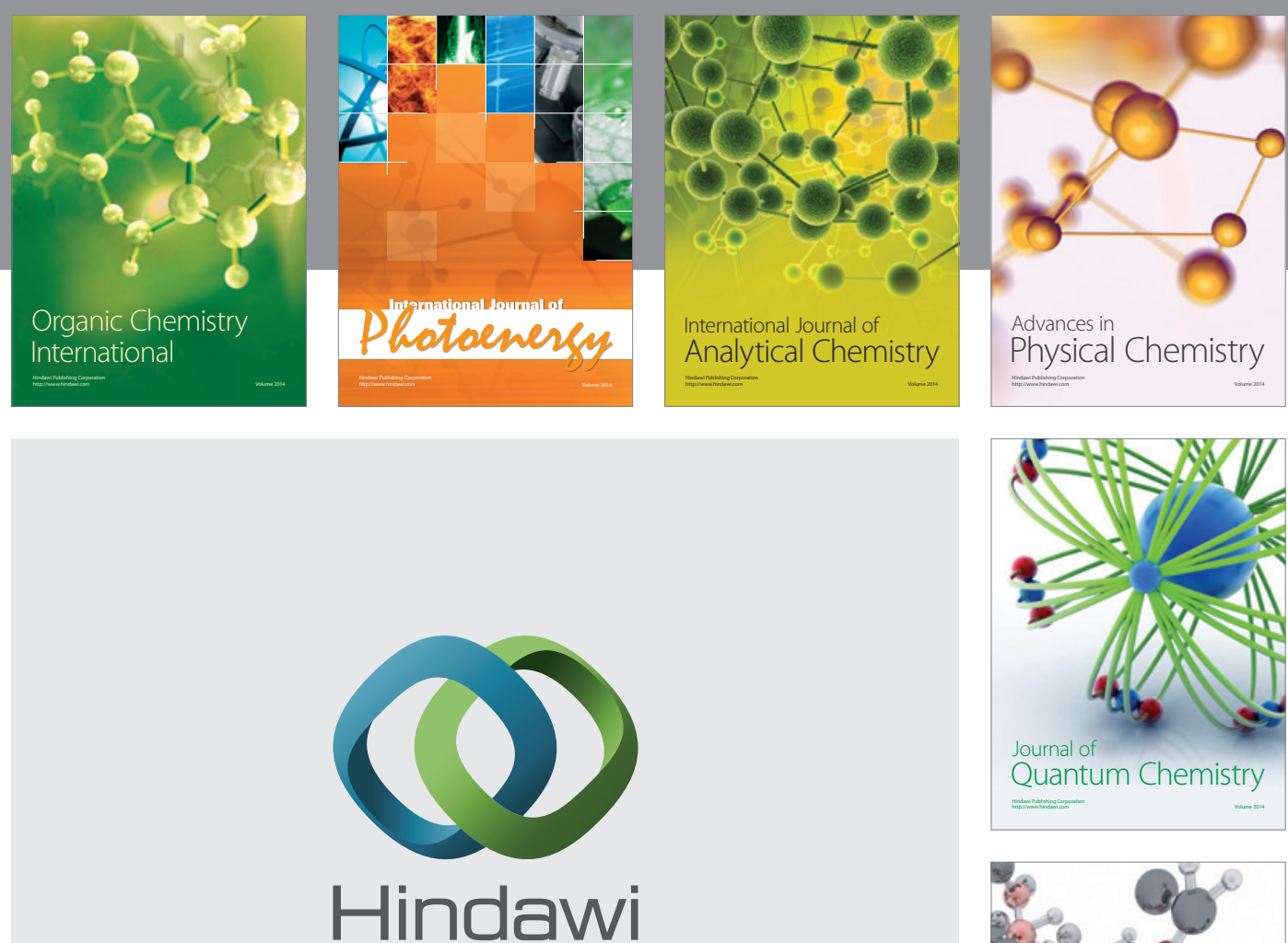

Submit your manuscripts at

http://www.hindawi.com

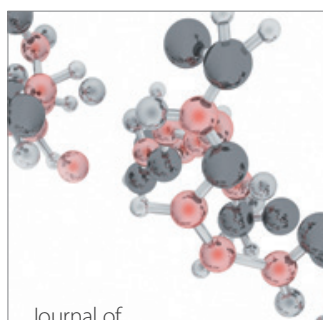

Analytical Methods

in Chemistry

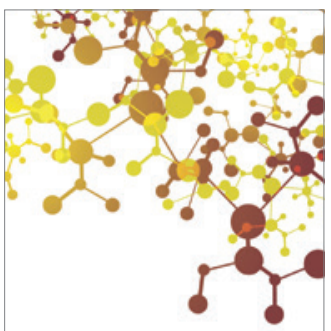

Journal of

Applied Chemistry

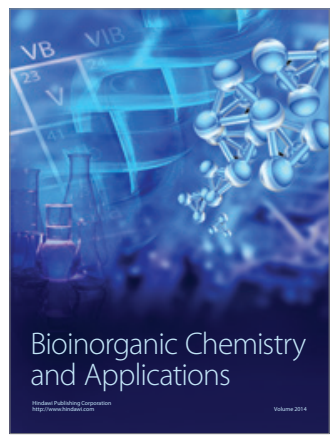

Inorganic Chemistry
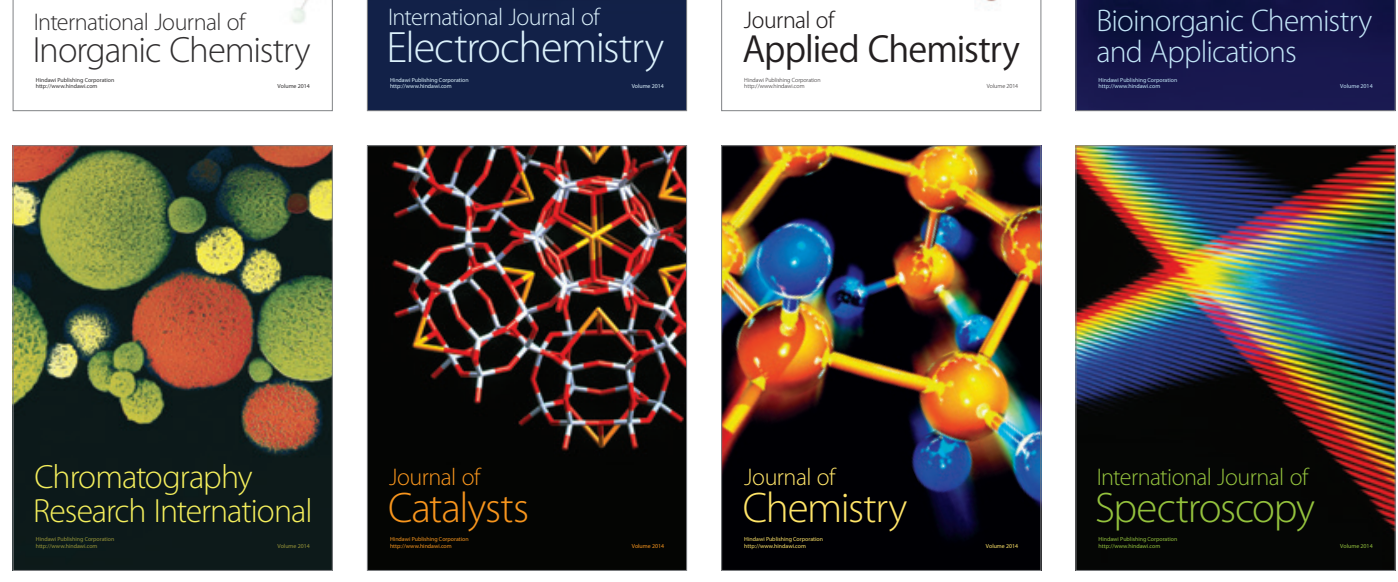